\title{
PENGARUH KOMITMEN ORGANISASI TERHADAP ORGANIZATIONAL CITIZENSHIP BEHAVIOR DI TOPAS GALERIA HOTEL
}

\author{
Hesti Sugesti $^{1}$, Yusriyya Zalfa Saqila ${ }^{2}$ \\ Prodi D4 Manajemen Perusahaan, Politeknik Pos Indonesia ${ }^{1}$ \\ email : hestisugesti@poltekpos.ac.id \\ Prodi D4 Manajemen Perusahaan, Politeknik Pos Indonesia ${ }^{2}$ \\ email : yusriyyazal@gmail.com
}

\begin{abstract}
Abstrak
Efektifitas sebuah perusahaan dapat dilihat dari bagaimana interaksi kerja pada tingkat individu maupun kelompok, dan sistem-sistem perusahaan yang menghasilkan output manusia yang memiliki komitmen terhadap perusahaan dan juga organizational citizenship behavior. Dalam penelitian ini, peneliti ingin mengetahui gambaran komitmen organisasi, organizational citizenship behavior dan bagaimana pengaruh antara keduanya. Metode yang dilakukan adalah dengan menggunakan deskriptif kuantitatif dengan pengambilan sampel sejumlah 68 orang responden, adapun teknik pengumpulan data melalui observasi, kuesioner dan studi kepustakaan. Data diolah melalui uji validitas dan reliabilitas, statistika deskriptif, uji normalitas, uji linearitas, uji kolerasi, uji regresi linear sederhana, uji koefisien determinasi, uji f dan juga uji t. Gambaran komitmen organisasi pada karyawan dalam kategori sangat baik sedangkan gambaran organizational citizenship behavior karyawan dalam kategori baik. Didapatkan hasil bahwa komitmen organisasi berpengaruh positif dan signifikan terhadap organizational citizenship behavior. Saran untuk Topas Galeria Hotel diharapkan mampu memaksimalkan komitmen pada karyawan, semakin tinggi komitmen yang dimiliki oleh karyawan makan akan semakin tinggi juga perilaku organizational citizenship behavior.
\end{abstract}

Kata Kunci : Komitmen Organisasi, Organizational Citizenship Behavior.

\begin{abstract}
The effectiveness of a company can be seen from how the interaction works at the individual level of the group, and the systems of the company that produce human output that is committed to the company as well as organizational citizenship behavior. In this study, researchers wanted to know a picture of organizational commitment, organizational citizenship behavior and how the influence between the two. The method is to use quantitative descriptive with the sampling of a total of 68 respondents, as well as data collection techniques through observation, questionnaires and literature studies. The data is processed through validity and reliability tests, descriptive statistics, normality tests, linearity tests, coeration tests, simple linear regression tests, determination coefficient tests, $f$ tests and also t tests. The picture of the organization's commitment to employees in the category is excellent while the picture of organizational citizenship behavior of employees in the category is good. It was obtained that the organization's commitment had a positive and significant impact on the organizational citizenship behavior. The advice for Topas Galeria Hotel is expected to maximize the commitment to employees, the higher the commitment that employees have to eat will be more and more organizational citizenship behavior.
\end{abstract}

Keyword : Commitment Organization, Organizational Citizenship Behavior.

\section{PENDAhUluAN}

Organizational citizenship behavior berkaitan dengan perilaku atau tindakan seseorang karyawan diluar tanggung jawabnya. Dengan kemampuan berempati sesama rekan kerja karyawan dapat memahami tentang orang lain dan juga lingkungannya dan bagaimana menyelaraskannya dengan nilai-nilai yang dianut baik secara individu ataupun lingkungannya, sehingga muncul perilaku good citizen. Kemampuan kerja merupakan salah satu bagian dari organizational citizenship behavior yang dapat 
memberikan kinerja yang baik dalam bekerja. Didalam perusahaan jika karyawannya memiliki organizational citizenship behavior, maka karyawan akan dapat mengendalikan perilakunya sendiri sehingga mampu memilih perilaku terbaik yang akan menguntungkan kepentingan perusahaannya.

Dalam penelitian ini berdasarkan dengan hasil observasi di lapangan dan wawancara bersama Manager HRD dapat dikatakan bahwa tingkat organizational citizenship behavior karyawan di Topas Galeria masih kurang, hal ini diindikasi dari beberapa masalah yang timbul berdasarkan indikator dari organizational citizenship behavior itu sendiri seperti karyawan jarang membantu rekan kerja yang berhalangan hadir, karyawan suka mengeluh karyawan kurang berpartisipasi dalam kegiatan yang dilakukan oleh perusahaan. Hal tersebut di dukung dengan hasil penelitian yang menunjukkan bahwa indikator dari masalah tersebut berada dalam kategori cukup dan memiliki persentase yang lebih kecil dibandingkan dengan indikator lainnya.

Menurut Organ dalam Kurniawan (1015), komitmen organisasi merupakan salah satu variabel yang memiliki keterkaitan yang cukup erat dengan organizational citizenship behavior. Kuuruzum dalam Haris (2017) mengemukakan bahwa perusahaan pada bidang jasa diharapkan untuk memperhatikan pada setiap keperluan karyawannya sehingga karyawan akan merasa puas dan memberikan komitmen yang tinggi, semakin besar kontribusi yang dilakukan oleh karyawan maka akan semakin berdampak pada tercapainya tujuan perusahaan.

Berdasarkan uraian diatas maka untuk menjawab permasalah tersebut penulis menggunakan metode penelitian kuantitatif. Metode kuantitatif dipakai buat meneliti populasi atau sampel tertentu, dengan mengumpulkan informasi melalui instrumen penelitian, analisis informasi bersifat kuantitatif atau statistik dengan maksud buat menguji hipotesis yang sudah dibuat.

\subsection{Tujuan Penelitian}

Berdasarkan latar belakang penelitian, maka tujuan dalam penelitian ini sebagai berikut :

1. Untuk mengetahui gambaran komitmen organisasi karyawan Topas Galeria Hotel.

2. Untuk mengetahui gambaran organizational citizenship behavior karyawan Topas Galeria Hotel.

3. Untuk mengetahui bagiamana pengaruh komitmen organisasi terhadap organizational citizenship behavior karyawan Topas Galeria Hotel.

\subsection{Tinjauan Pustaka}

1. Komitmen Organisasi

Komitmen organisasi merupakan kemauan kuat seseorang untuk tetap berada dalam suatu organisasi, kemauan yang didukung dengan usaha keras agar sesuai dengan apa yang diharapkan oleh organisasi tersebut dan juga kepercayaan tertentu dalam menerima nilai dan pencapaian organisasi. Sehingga dapat dikatakan sikap yang dapat menggambarkan kesetiaan karyawannya pada organisasi tersebut dan kelanjutannya dimana karyawan mengutarakan perhatiannya kepada organisasi dan pencapaian juga kemajuan yang terus berlanjut. (Nurandini, Lataruva, Prof, \& Sh, 2014).

Pendapat lain dikemukakan oleh (Fanani, Djati, \& Silvanita, 2016) menyatakan komitmen organisasi ialah suatu perilaku yang diperlihatkan oleh seseorang dengan melibatkan diri serta rasa kesetiaan kepada organisasi. Dan kemauan untuk tetap bertahan dan tidak ingin meninggalkan organisasi apapun yang terjadi. Sedangkan (Dewanggana, Paramita, \& Andi, 2016) menggambarkan komitmen organisasi sebagai kemauan yang kuat sebagai bagian dari organisasi, kemauan dengan usaha keras sesuai yang diharapkan organisasi dan kepercayaan yang dianut dan merima segala nilai dan pencapaian organisasi. Robbins (dalam Nurandini et al., 2014) membagi komitmen menjadi tiga dimensi diantaranya : Komitmen afektif, komitmen normatif dan komitmen kontinuan.

\section{Organizational Citizenship Behavior}

Organizational citizenship behavior adalah suatu tindakan positif yang dilakukan oleh seseorang, keterkaitannya dalam organisasi ialah tindakan bantu membantu dalam hal pekerjaan yang dilakukan oleh seseorang. Partisispasi yang diberikan oleh karyawan dalam bentuk pekerjaan diluar tanggung jawabnya itu sendiri. Karyawan dengan senang hati membantu beban tugas rekan kerja lainnya yang mana dengan tindakan positif tersebut dapat membuat produktifitas organisasi tersebut menjadi lebih baik atau meningkat, (Widiastuti \& Suaris, 2017). 
Pendapat lain yang dikemukakan oleh Tampi (2013) bahwa "Organization citizenship behavior dapat dijelaskan sebuah tindakan double fungsi, namun tidak adanya pemberian penghargaan atau reward dan juga hukuman secara resmi oleh organisasi, namun hal tersebut memberikan banyak manfaat terhadap organisasi dengan meningkatnya efektifitas dan produktifitas organisasi tersebut."

Pendapat lain menurut Dewanggana, Paramita, \& Andi (2016) mengungkapkan bahwa "Organizational citizenship behavior ialah partisipasi seseorang diluar tanggung jawabnya dalam melakukan pekerjaan. Tindakan tersebut menyertakan beberapa tindakan seperti menolong sesama rekan kerja, mengerjakan hal-hal ekstra, taat pada aturan dan kebijakan perusahaan. Tindakan tersebut dapat menjadi nilai tambah dan merupakan tindakan positif yang dimiliki oleh karyawan dalam bekerja." Lima dimensi yang umum digunakan dalam organizational citizenship behavior menurut (Organ, dalam Kurniawan 2015) yaitu : Altruism, Conscientiousness, Sportmanship, Civic Virtue, Courtes.

\section{METODE PENELITIAN}

\subsection{Uji Validitas}

Menurut Sugiyono (2017:121) suatu instrumen atau item pernyataan dalam suatu kuesioner dikatakan valid artinya alat ukur yang digunakan dalam meperoleh data itu valid untuk bisa mengukur sesuatu. Dalam hal ini peneliti ingin menguji variabel x yaitu komitmen organisasi dan variabel y organizational citizizenship behavior, apakah kedua variabel tersebut valid dan layak untuk diuji. Berdasarkan hasil uji validitas pada seluruh item variabel komitmen organisasi dan organizational citizenship behavior dengan menggunakan taraf signifikan 5\% atau 0,05 dengan nilai 0,361 dapat dinyatakan valid. Pada penelitian ini $\mathrm{r}$ hitung $>\mathrm{r}$ tabel dan memberikan nilai Cronchbach Alpha $>0,361$.

\subsection{Uji Reliabilitas}

Menurut Sugiyono (2017:121) instrumen atau pernyataan yang reliabel artinya instrumen tersebut bisa digunakan lebih dari satu kali dalam mengukur objek yang sama dan dapat memperoleh data yang sama pula. Uji reliabilitas menggunakan koefisien alpha $(\alpha)$ dari Cronbach dengan memberikan nilai $>0,60$. Berdasarkan tabel diatas dapat diketahui bahwa cronbach alpha yang di peroleh lebih dari 0,60 pada variabel komitmen organisasi yaitu sebesar 0,832 dan pada variabel organizational citizenship behavior yaitu sebesar 0,852 . Hal ini menunjukkan bahwa seluruh item yang digunakan sudah reliable, dan dapat digunakan dalam penelitian.

\subsection{Statistik Deskriptif}

Teknik analisis data yang digunakan dalam penelitian ini adalah analisis statistik deskriptif. Menurut Sugiyono (2015:17) statistik deskriptif dilakukan dengan menganalisis data melalui menggambarkan data yang terkumpul. Dalam penelitian ini, peneliti akan menggambarkan bagaimana variabel x yaitu komitmen organisasi dan variabel y organizational citizizenship behavior yang ada pada karyawan Topas Galeria Hotel berdasarkan dengan hasil survei menggunakan kuesioner yang telah disebar sebelumnya.

\subsection{Uji Asumsi Klasik}

Uji normalitas digunakan untuk menguji apakah model regresi, variabel $\mathrm{X}$ dengan variabel Y memiliki distribusi normal ataukah tidak. Data yang memiliki normalitas yang baik apabila jumlah nilai signifikansinya $>$ dari $\alpha$ yang ditetapkan yaitu 0,05 atau $5 \%$, (Kurniawan, 2015). Uji normalitas dalam penelitian ini menggunakan teknik One Sample Kolmogorov.

Uji linearitas bertujuan untuk mengetahui apakah dua variabel tersebut memiliki hubungan yang linear atau tidak. Data yang baik seharusnya memiliki hubungan yang linear antara variabel (X) dan juga variabel (Y). Uji linearitas merupakan syarat sebelum dilakukannya uji regresi linear sederhana, (Forester, 2016). Uji korelasi dilakukan agar dapat mengetahui bagaimana besaran hubungan antara variabel independen dengan variabel dependen yang dalam penelitian ini adalah komitmen organisasi (X) terhadap organizational citizenship behavior (Y). 


\section{HASIL DAN PEMBAHASAN \\ 3.1Analisis Deskriptif}

Tabel 1. Rekapitulasi Tanggapan Responden Variabel Komitmen Organisasi

\begin{tabular}{|c|l|c|c|}
\hline No & \multicolumn{1}{|c|}{ Dimensi } & Skor Total & Persentase \\
\hline 1 & Komitmen Afektif & $\mathbf{3 0 8 . 8}$ & $\mathbf{9 0 . 8 \%}$ \\
\hline 2 & Komitmen Normatif & $\mathbf{3 1 1 . 1}$ & $\mathbf{9 1 , 5 \%}$ \\
\hline 3 & Komitmen Kontinuan & $\mathbf{2 9 3 . 8}$ & $\mathbf{8 6 . 4 \%}$ \\
\hline & RATA-RATA SKOR & \multicolumn{2}{|c|}{$\mathbf{8 9 . 6 \%}$} \\
\hline & RATA-RATA \% & \multicolumn{2}{c}{} \\
\hline
\end{tabular}

Berdasarkan tabel diatas, penelitian variabel Komitmen Organisasi secara keseluruhan memiliki ratarata skor total yang didapat 304,6 dan rata-rata persentase sebesar $89,6 \%$. Adapun skor tertinggi terdapat pada dimensi komitmen normatif dengan persentase $91,5 \%$ dari rata-rata sebanyak 311.1 dan sebaliknya skor terendah terdapat pada dimensi kontinuan dengan persentase 86,4\% dari rata-rata 293.8. Hal ini menunjukan bahwa komitmen organisasi karyawan Topas Galeria Hotel Bandung berada pada kategori sangat baik secara keseluruhan.

Tabel 2. Rekapitulasi Tanggapan Responden Variabel $O C B$

\begin{tabular}{|c|c|c|c|}
\hline No & Dimensi & Rata-rata & Persentase \\
\hline 1 & Altruism & $\mathbf{2 3 4 . 7}$ & $\mathbf{6 9 , 0 \%}$ \\
\hline 2 & Conscientiousness & $\mathbf{2 9 8 . 5}$ & $\mathbf{8 7 . 7 \%}$ \\
\hline 3 & Sportmanship & $\mathbf{2 2 5}$ & $\mathbf{6 6 , 1 \%}$ \\
\hline 4 & Civic True & $\mathbf{2 2 8 . 2}$ & $\mathbf{6 7 , 1 \%}$ \\
\hline 5 & Courtesy & $\mathbf{2 5 9 . 1}$ & $\mathbf{7 6 , 2 \%}$ \\
\hline & RATA-RATA SKOR & \multicolumn{2}{|c|}{$\mathbf{2 4 9 . 1}$} \\
\hline \multicolumn{2}{|c|}{$\mathbf{7 3 . 2 2 \%}$} \\
\hline
\end{tabular}

Berdasarkan tabel diatas, penelitian variabel Organizational Citizenship Behavior secara keseluruhan memiliki rata-rata skor total yang didapat 249.1 dan rata-rata persentase sebesar $73,22 \%$. Adapun skor tertinggi terdapat pada dimensi conscientiousness dengan persentase $87,7 \%$ dari rata-rata sebanyak 298.5 dan sebaliknya skor terendah terdapat pada dimensi sportmanship dengan persentase $66,1 \%$ dari rata-rata 225. Hal ini menunjukan bahwa organizational citizenship behavior karyawan Topas Galeria Hotel Bandung berada pada kategori baik secara keseluruhan.

\subsection{Pengujian Hipotesis}

$\mathrm{H}_{\mathrm{o}}$ : Komitmen organisasi (X) tidak berpengaruh positif dan signifikan terhadap organizational citizenship behavior (Y) di Topas Galeria Hotel.

$\mathrm{H}_{\mathrm{a}}$ : Komitmen organisasi (X) berpengaruh positif dan signifikan terhadap organizational citizenship behavior (Y) di Topas Galeria Hotel.

Tabel 3. Hasil Uji Normalitas

\begin{tabular}{|l|r|r|}
\hline \multicolumn{3}{|c|}{ One Sample Kolmogorov-Smirnov Test } \\
\hline & $\begin{array}{c}\text { Tingkat } \\
\text { Kesalahan }\end{array}$ & $\begin{array}{c}\text { Unstandardized } \\
\text { Residual }\end{array}$ \\
\hline N & & 30 \\
\hline Asymp Sig. (2-tailed) & 0,05 &, $200^{\text {cd }}$ \\
\hline \multicolumn{2}{|c|}{ Sumber: Data Olahan SPSS, 2020 }
\end{tabular}

Berdasarkan tabel diatas dapat diketahui bahwa data berdistribusi normal, karena memiliki nilai signifikan lebih besar $(>)$ dengan tingkat kesalahan $(\alpha)$ 5\% atau 0,05 yaitu 0,200 sehingga dapat dikatakan bahwa data tersebut layak untuk diteliti. 
Tabel 4. Hasil Uji Linearitas

\begin{tabular}{|c|c|c|}
\hline \multicolumn{3}{|l|}{ ANOVA Table } \\
\hline $\begin{array}{l}\mathrm{OCB}(\mathrm{Y}) * \text { Komitmen } \\
\text { Organisasi }(\mathrm{X})\end{array}$ & $\begin{array}{c}\text { Tingkat } \\
\text { kesalahan }\end{array}$ & Sig. \\
\hline Deviation from Linearity & 0,05 &, 111 \\
\hline
\end{tabular}

Berdasarkan hasil uji linearitas diketahui bahwa nilai signifikansi pada Deviation from Linearity sebesar 0,111 yang artinya lebih besar dari 0,05 , maka dapat dikatakan bahwa terdapat hubungan yang linear antara komitmen organisasi dan organizational citizenship behavior.

Tabel 5. Hasil Uji Kolerasi

\begin{tabular}{|c|c|c|c|}
\hline \multicolumn{4}{|c|}{ Correlations } \\
\hline & & $\begin{array}{c}\text { Komitmen } \\
\text { Organisasi } \\
(\mathrm{X}) \\
\end{array}$ & $\begin{array}{c}\text { Organizational } \\
\text { Citizenship } \\
\text { Behavior (Y) }\end{array}$ \\
\hline $\mathrm{X}$ & Sig. (2-tailed) & &, 004 \\
\hline & Person Coleration & & 506 \\
\hline $\mathrm{Y}$ & Sig. (2-tailed) &, 004 & \\
\hline & Person Coleration & 506 & \\
\hline
\end{tabular}

Sumber: Hasil Olahan SPSS, 2020

Berdasarkan tabel diatas dapat diketahhui bahwa nilai signifikan untuk varibael komitmen organisasi (X) adalah $0,004<0,1$ yang artinya komitmen organisasi $(\mathrm{X})$ berkolerasi terhadap organizational citizenship behavior (Y). Berikut tabel untuk mengetahui seberapa kuat hubungan antara variabel yang digunakan dalam penelitian ini pada tabel dibawah sebagai berikut :

Tabel 6. Hasil Uji Kolerasi

\begin{tabular}{|c|c|c|c|c|}
\hline No & Variabel & $\begin{array}{c}\text { Person } \\
\text { Coleration }\end{array}$ & $\begin{array}{c}\text { Interval } \\
\text { Koefisien }\end{array}$ & $\begin{array}{c}\text { Tingkat } \\
\text { Hubungan }\end{array}$ \\
\hline 1 & $\begin{array}{l}\text { Komitmen Organisasi } \\
\text { dan Organizational } \\
\text { Citizenship Behavior. }\end{array}$ & 0,506 & $0,40-0,599$ & Sedang \\
\hline \multicolumn{4}{|c|}{ Sumber: Data Olahan, 2020 } \\
\hline
\end{tabular}

Berdasarkan tabel diatas dapat diketahui bahwa komitmen organisasi sebagai variabel $\mathrm{X}$ dan organizational citizenship behavior sebagai variabel Y memiliki nilai kolerasi sebesar 0,506 dan berada dalam interval koefisien 040,-0,599 yang artinya berada pada tingkat hubungan yang sedang. Maka dapat dikatakan bahwa kedua variabel memiliki hubungan yang sedang. 
Tabel 7. Hasil Uji Regresi Sederhana

\begin{tabular}{|c|c|c|c|c|c|}
\hline $\begin{array}{l}\text { Regresi } \\
\text { Sederhana }\end{array}$ & \multicolumn{2}{|c|}{$\begin{array}{l}\text { Unstandardized } \\
\text { Coefficients }\end{array}$} & \multirow[b]{2}{*}{$t_{\text {tabel }}$} & \multirow[b]{2}{*}{$t_{\text {hitung }}$} & \multirow[b]{2}{*}{ Sig } \\
\hline & B & Std Error & & & \\
\hline Constant & 37,880 & 4,198 & & 9,023 &, 000 \\
\hline $\begin{array}{r}\text { Komitmen } \\
\text { Organiasi }(\mathrm{X})\end{array}$ & ,302 & 0,97 & 1,701 & 3,107 &, 004 \\
\hline
\end{tabular}

Berdasarkan hasil uji diatas dengan menggunakan program komputer IBM SPSS Statistic 23, SPSS (Statistic Package for Social Sciences) yang diolah dengan menggunakan analisis regresi linear sederhana diketahui adalah nilai constant (a) adalah 37,880 sedangkan nilai trust (b) adalah 0,302, sehingga persamaan regresinya adalah:

$\mathbf{Y}=\mathbf{a}+\mathbf{b X}$

$\mathbf{Y}=\mathbf{3 7 , 8 8 0}+\mathbf{0 , 3 0 2 X}$

Dimana :

$\mathrm{X}=$ Komitmen Organisasi

$\mathrm{Y}=$ Organizational Citizenship Behavior

Koefisien persamaan regresi linear sederhana diatas dapat diartikan bahwa nilai positif melambangkan jika komitmen organisasi ditingkatkan satu satuan maka organizational citizenship behavior akan meningkat 0,302 satuan. Nilai konstanta artinya adalah jika komitmen organisasi tidak ditingkatkan maka organizational citizenship behavior sebesar 4,561. Jika diliat dari nilai signifikan diketahui bahwa komitmen organisasi sebagai variabel X diketahui memiliki nilai signifikan sebesar 0,004 yang artinya lebih kecil dari 0,05, dapat dikatakan komitmen organisasi berpengaruh positif terhadap organizational citizenship behavior.

Tabel 8. Hasil Uji Koefisien Determinasi

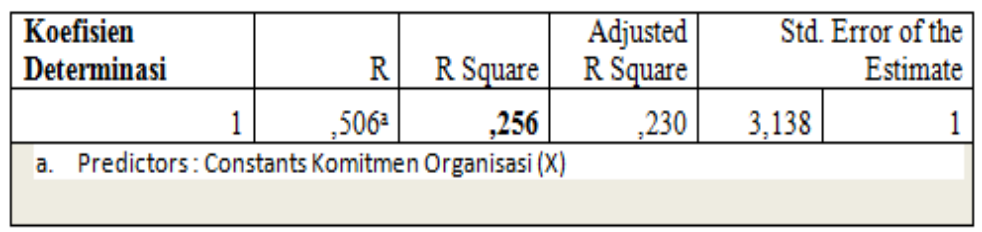

Sumber: Data Olahan, 2020

Berdasarkan uji koefisien determinasi diatas didapat nilai $\mathrm{R}$ square 0,256 dimana $25 \%$ bagian dari komitmen organisasi bisa diuraikan dengan variabel independen dan sisanya $75 \%$ diuraikan oleh fakor lain yang tidak ada pada penelitian ini.

Tabel 9. Hasil Uji F Stimultan

\begin{tabular}{|r|r|r|r|r|r|}
\hline Uji F Stimultan & $\begin{array}{c}\text { Sum Of } \\
\text { Squares }\end{array}$ & \multicolumn{1}{c|}{ Df } & $\mathrm{f}_{\text {tabel }}$ & $\mathrm{f}_{\text {hitung }}$ & sig. \\
\hline Regression & 95,058 & 1 & 3,34 & 9,653 &, $\mathbf{0 0 4}^{\mathrm{b}}$ \\
\hline Residual & 275,742 & 28 & & & \\
\hline Total & 370,800 & 29 & & & \\
\hline $\begin{array}{l}\text { a. Dependent Variabel: OrganizationalCitizenship Behavior (Y) } \\
\text { b. Predictors : Constants Komitmen Organisasi (X) }\end{array}$ \\
\hline \multicolumn{7}{|c|}{ Sumber. Data Olahan 2020 } \\
\hline
\end{tabular}

Berdasarkan hasil uji $\mathrm{F}$ stimultan diatas diperoleh nilai $\mathrm{f}_{\text {hitung }}$ sebesar 9.653 dengann tingkat signifikan 0,004. Dilihat dari taraf siginifikan 0,05 maka 0,004 < 0,05, dan dinyatakan terdapat pengaruh secara stimultan terhadap organizational citizenship behavior. 
Tabel 10. Hasil Uji T Parsial

\begin{tabular}{|c|c|c|c|c|c|}
\hline \multirow[t]{2}{*}{ Uji T Parsial } & \multicolumn{2}{|c|}{$\begin{array}{l}\text { Unstandardized } \\
\text { Coefficients }\end{array}$} & \multirow[b]{2}{*}{$t_{\text {tabel }}$} & \multirow[b]{2}{*}{$\mathrm{t}_{\text {hitung }}$} & \multirow[b]{2}{*}{ sig. } \\
\hline & $\mathrm{B}$ & Std Error & & & \\
\hline Constant & 39.813 & 5.139 & 1,701 & 7.747 &, 000 \\
\hline $\begin{array}{r}\text { Komitmen } \\
\text { Afektif }\end{array}$ &,- 107 &, 224 & 1,701 &,- 478 &, 636 \\
\hline $\begin{array}{c}\text { Komitmen } \\
\text { Normatif }\end{array}$ & ,788 & ,313 & 1,701 & 2.519 & ,018 \\
\hline $\begin{array}{l}\text { Komitmen } \\
\text { Kontinuan }\end{array}$ & .114 & 272 & 1,701 & 418 &, 679 \\
\hline
\end{tabular}

Berdasarkan hasil uji t parsial diatas diketahui bahwa hanya dimensi komitmen normatif yang menunjukkan taraf signifikan < 0,05 yaitu 0,18 sedangkan dimensi lain menunjukkan taraf signifikan > 0,05 sehingga dapat dinyatakan bahwa dari ketiga dimensi diatas, komitmen normatif adalah dimensi yang berpengaruh terhadap organizatioal citizenship behavior.

Dari hasil pengujian hipotesis diatas dapat dikatakan bahwa komitmen organisasi berpengaruh positif dan signifikan terhadap organizational citizenship behavior, yang mana artinya hipotesis dalam penelitian ini dapat diterima. Dalam kasus ini karyawan Topas Galeria Hotel memiliki komitmen dan loyalitas yang tinggi terhadap perusahaan, hal ini di dukung dengan data karakteristik responden yang di dominasi oleh karyawan yang sudah bekerja lebih dari 5-10 tahun keatas, yang mana artinya kebijakan baru yang dibuat oleh karyawan bisa jadi hanya mempengaruhi karyawan dengan lama kerja dibawah 5 tahun, karena kayawan yang terikat dengan perusahaan dalam jangka waktu yang singkat tidak merasa ada keterkaitan dan tidak ikut memiliki perusahaan dalam dirinya. Hal ini sejalan dengan teori yang dikemukakan oleh (Kurniawan, 2015) bahwa organizational citizenship behavior muncul disebabkan oleh faktor-faktor dalam sebuah perusahaan atau organisasi, salah satunya adalah komitmen karyawan. Karyawan yang memiliki komitmen yang tinggi pada perusahaan ataupun organisasi, karyawan tersebut akan dengan senang hati melakukan hal apapun yang diyakini dapat mengembangkan perusahaan karena adanya rasa percaya.

\section{KESIMPULAN DAN SARAN}

\subsection{Kesimpulan}

Berdasarkan hasil analisis dan pembahasan yang telah diuraikan pada bab sebelumnya, maka dalam penelitian ini dapat ditarik kesimpulan sebagai berikut :

1. Berdasarkan hasil rekapitulasi diketahui bahwa dimensi kontinuan memiliki persentase paling rendah dilihat dari indikator ketergantungan dan kepemilikan karyawan pada organisasi atau perusahaan, dan dimensi komitmen normatif memiliki persentase paling tinggi dilihat dari indikator tanggung jawab dan kesetiaan pada organisasi.

2. Berdasarkan hasil rekapitulasi dimensi civic true memiliki persentase paling rendah dilhat dari indikator karyawan mengikuti perubahan dan dimensi conscientiousness memiliki persentase paling tinggi dilihat dari indikator karyawan tepat waktu dan tidak mengambil jeda ekstra istirahat.

3. Uji hipotesis pada penelitian ini diterima dimana terdapat pengaruh positif dan signifikan pada organizational citizenship behavior di Topas Galeria Hotel.

\subsection{Saran}

Berdasarkan kesimpulan tersebut, maka dalam penelitian ini penulis memberikan masukan yang sekiranya dapat menjadi masukan dan bermanfaat bagi Topas Galeria Hotel, sebagai berikut :

1. Topas Galeria Hotel sebagai pelaku organisasi hendaknya memaksimalkan komitmen pada karyawan. Karena untuk memaksimalkan produktifitas dan tercapai tujuan perusahaan dibutuhkan karyawan yang memiliki komitmen yang tinggi sehingga karyawan nantinya akan dengan senang hati dan secara sukarela melakukan apapun demi kemajuan Topas Galeria Hotel. Komitmen yang tinggi makan akan meningkatkan perilaku organizational citizenship behavior yang tinggi juga pada karyawan. 
2. Topas Galeria Hotel juga hendaknya memperhatikan faktor-faktor lain yang mempengaruhi perilaku organizational citizesnhip behavior, seperti kepuasan kerja yang dirasakan oleh karyawan, motivasi, budaya organisasi dan lainnya. Semakin banyak faktor yang bisa dianalisis sejak dini maka akan bisa dicegah dan hindari dampak negatifnya oleh Topas Galeria Hotel.

3. Mengevaluasi setiap kebijakan, dan peraturan dalam perusahaan secara berkala, agar dapat dimaksimalkan sesuai dengan keadaan dan kebutuhan bukan hanya untuk Topas Galeria Hotel tetapi juga karyawannya.

\section{DAFTAR PUSTAKA}

Dewanggana, B. D., Paramita, P. D., \& Andi, T. H. (2016). Pengaruh Komitmen Organisasi, Kepuasan Kerja, Budaya Organisasi Terhadap Organizational Citizenship Behavior (OCB) Yang Berdampak Pada Prestasi Kerja Karyawan (Studi pada PT. PLN APP Semarang). Journal of Management, 2(2), 1-10.

Kadir. (2019). Statistika Terapan: Konsep, Contoh dan Analisis Data dengan Program SPSS/Lisrel dalam Penelitian, Depok: Rajawali Pers.

Kurniawan, A. (2015). Pengaruh Komitmen Organisasi Terhadap Organizational Citizenship Behavior (OCB) PT X Bandung. Jurnal Manajemen Maranatha, 15(1), 95-118.

Sugesti, Hesti.2019. Buku Pedoman Tugas Akhir. Bandung : Politeknik Pos Indonesia.

Sugiyono. (2017). Metode Penelitian Kuantitatif, Kualitatif dan R\&D. Bandung: Alfabeta, cv.

Sugiyono.2017. Metode penelitian kuantitatif, kualitatif, dan kombinasi (Mixed Methods). Bandung: Alfabeta.

Nurandini, A., Lataruva, E., Prof, J., \& Sh, S. (2014). Analisis Pengaruh Komitmen Organisasi Terhadap Kinerja Karyawan (Studi Pada Pegawai Perum Perumnas Jakarta). 11(1), 78-91. https://doi.org/10.14710/jsmo.v11i1.13164

Widiastuti, T., \& Suaris, S. (2017). PENGARUH KOMITMEN ORGANISASI DAN KEPUASAN KERJA TERHADAP ORGANIZATIONAL CITIZENSHIP BEHAVIOUR ( OCB ) ( Studi pada Karyawan Kantor Konsultan Manajemen Rizqi ) The Influence of Organizational Commitment and Job Satisfaction on Organizational Citizenship Be. Fokus Ekonomi, 12(1), 81-98. Retrieved from http://www.ejournal.stiepena.ac.id/index.php/fe/article/view/165

Wijaya, C. (2017). Perilaku individu organisasi. 